\title{
La documentación de las lenguas patagónicas en el gabinete de Samuel A. Lafone Quevedo. El Vocabulario Guenaken
}

La documentation des langues de Patagonie dans le cabinet de Samuel A. Lafone Quevedo. Le vocabulaire guenaken

The documentation of Patagonian languages in Samuel A. Lafone Quevedo's cabinet. The Guenaken Vocabulary

\section{Marisa Malvestitti y María Emilia Orden}

\section{(2) OpenEdition}

\section{Journals}

Edición electrónica

URL: https://journals.openedition.org/jsa/17512

DOI: $10.4000 /$ jsa. 17512

ISSN: $1957-7842$

Editor

Société des américanistes

Edición impresa

Fecha de publicación: 20 diciembre 2019

Paginación: 133-164

ISSN: 0037-9174

Referencia electrónica

Marisa Malvestitti y María Emilia Orden, «La documentación de las lenguas patagónicas en el gabinete de Samuel A. Lafone Quevedo. El Vocabulario Guenaken», Journal de la Société des américanistes [En línea], 105-2 | 2019, Publicado el 20 diciembre 2019, consultado el 03 septiembre 2022. URL: http://journals.openedition.org/jsa/17512 ; DOl: https://doi.org/10.4000/jsa. 17512 


\title{
La documentación de las lenguas patagónicas en el gabinete de Samuel A. Lafone Quevedo. El Vocabulario Guenaken
}

\author{
Marisa Malvestitti y María Emilia Orden *
}

\begin{abstract}
En el último tercio del siglo XIX, en pleno auge de la descripción de los grupos indígenas de Latinoamérica, Samuel A. Lafone Quevedo (1835-1920) comenzó su labor de recolección y descripción lingüísticas. Preocupado por la configuración de un mapa étnico americano, estableció patrones léxico-gramaticales que permitieran reconocer vínculos genéticos o procesos de difusión. En esa búsqueda se entrevistó en el Museo de La Plata con un hablante de günün a iajüch (entonces conocida como guenaken o puelche), con quien elicitó un vocabulario que consta de 116 entradas y permaneció inédito entre sus papeles de trabajo. En este artículo ofrecemos acceso a la fuente, que amplía los registros existentes sobre este idioma, y explicamos cómo la documentación del filólogo se realizó con un patrón estandarizado en diálogo con la bibliografía previa y con fines contrastivos con otras lenguas patagónicas. [Palabras clave: documentación lingüística, guenaken, Museo de La Plata, Lafone Quevedo.]
\end{abstract}

La documentation des langues de Patagonie dans le cabinet de Samuel A. Lafone Quevedo. Le vocabulaire guenaken. Au cours du dernier tiers du XIX siècle, en plein boom de la description des ethnies indigènes d'Amérique latine, Samuel A. Lafone Quevedo (1835-1920) s'engagea dans un travail de récolte et de description linguistique. Tentant de dresser une carte ethnique de l'Amérique, il recherchait des régularités lexico-grammaticales qui permettraient de reconnaître des liens génétiques ou des processus de diffusion. C'est dans cette optique qu'il enquêta au musée de La Plata avec un locuteur du günün a iajüch (alors connu sous les noms de guenaken ou de puelche), avec qui il élicita un vocabulaire contenant 116 entrées, resté inédit parmi ses documents de travail. Dans cet article, nous donnons accès à la source, ce qui augmente les données disponibles sur cette langue, et nous expliquons comment la documentation du philologue a été réalisée conformément à un modèle standardisé, en dialogue avec la bibliographie antérieure et afin d'établir des contrastes avec les autres langues de Patagonie. [Mots-clés : documentation linguistique, Guenaken, musée de La Plata, Lafone Quevedo.]

* M. Malvestitti: Universidad Nacional de Río Negro [mmalvestitti@unrn.edu.ar]; M. E. Orden: Universidad Nacional de La Pampa [mariaemiliaorden@gmail.com]. 
The documentation of Patagonian languages in Samuel A. Lafone Quevedo's cabinet. The Guenaken Vocabulary. Towards the end of the nineteenth century, during the boom of the description of indigenous groups in Latin America, Samuel A. Lafone Quevedo (1835-1920) began his work of collection and linguistic description. Concerned about the configuration of a Latin American ethnic map, he established lexical-grammatical patterns in order to detect structural patterns allowing the recognition of genetic links or diffusion processes. During his research at the La Plata Museum, Lafone Quevedo met a speaker of the Günün a iajüch language (also known as Guenaken or Puelche) and elicited with him a wordlist of 116 entries which has remained unpublished until now. In this text we offer access to the source, which expands existing records about this language, and we explain that the philologist's elicitation was carried out according to a standardized method, supported by the previous bibliography and comparison with other Patagonian languages. [Key words: Linguistic documentation, Guenaken, La Plata Museum, Lafone Quevedo.]

En el último tercio del siglo xix la formación de los museos en la Argentina requirió del acopio de ejemplares paleontológicos y naturales, así como de bienes tangibles y simbólicos concernientes a los pueblos originarios que se encontraban dentro de los límites del territorio nacional. De modo sistemático, desde el Museo de La Plata (en adelante, MDLP) se impulsaron campañas a la Patagonia con el doble fin de mapear el territorio y reunir tales elementos, y de ese modo contribuir al desarrollo de las ciencias locales enmarcadas en el americanismo (Podgorny y Lopes 2013).

En ese periodo, así como en las dos primeras décadas del siglo xx, antropólogos y naturalistas vinculados con el Museo realizaron distintas documentaciones sobre las lenguas de la región patagónica y del norte del país. Entre los registros y los estudios producidos sobre los idiomas en la región sur se destacan, por su amplitud, las investigaciones lideradas por Roberto Lehmann-Nitsche (Malvestitti 2012, 2014, 2015; Malvestitti y Orden 2014). A ese conjunto se suman las anotaciones formuladas en el contexto de campañas de otros agentes vinculados con la institución: Francisco Pascasio Moreno (1879; Mitre 1909, I, p. 214-215), Carlos Ameghino (en Malvestitti 2018) y Carlos Burmeister (1891). En cambio, resulta menos conocida la labor de documentación y reflexión sobre las variedades patagónicas desarrollada en el MDLP por Samuel Alexander Lafone Quevedo (1835-1920), quien se desempeñó como encargado de la sección de "Arqueología y Lenguas Americanas" del museo durante el periodo de 1888 a 1906 y, desde ese año hasta su fallecimiento, revistió el cargo de director de la institución.

Los estudios que analizan la trayectoria biográfica de Lafone Quevedo se han concentrado en la diversidad de las investigaciones americanistas que realizó en relación con el folclore, la arqueología, la historia, la etnología y la lingüística (AAVV 1921, 1962; Furlong Cardiff 1964). Farro (2009, 2013) se refiere detalladamente a su enfoque teórico y metodológico en el terreno 
filológico, y expone las instrumentalidades empleadas para el abordaje de las lenguas guaycurúes, mataco-mataguayas y cacán. Describe así la forma en que su gabinete, con la ayuda de un escribiente, sistematizó un amplio corpus de datos lingüísticos a través de un riguroso trabajo de transcripción en cuadernillos de tapa de cartón "donde se ordenaban alfabéticamente las entradas, asentando en una columna los vocablos en idioma indígena y en una columna contigua sus equivalentes en castellano" (Farro 2013, p. 537). Estos recursos oficiaron como documentos de trabajo -aportando ejemplos concretos que sustentaban sus hipótesis sobre la afijación en las variedades americanas-y constituyen un antecedente para el trabajo comparativo posteriormente realizado en el marco del MDLP sobre dos lenguas de la Patagonia: tehuelche y günün a iajüch.

En este trabajo ${ }^{1}$ consideramos un aspecto de la tarea de documentación y análisis que Lafone Quevedo realizó sobre esta última lengua, genéticamente relacionada con las del tronco chon (Viegas Barros 2015) y denominada alternativamente en las fuentes de la época como "guenaken", "gennaken", "puelche" o "pampa". La misma contaba con pocas documentaciones previas en la época en que Lafone Quevedo se abocó a su análisis, y constituía una suerte de mito lingüístico, por un lado, cimentado en la ambigua clasificación del grupo y, por otro, por la singularidad que presentaba, pues de hecho no se asemejaba a ninguna de las lenguas con las que estaba en contacto al momento de ser relevada. Su elucidación resultaba así de crucial importancia, pues Lafone Quevedo (1898c; 1900) hipotetizaba que el "guenaken" constituía el "eslabón" entre las lenguas de Patagonia y de Chaco.

El análisis de sus manuscritos, publicaciones y correspondencia permite inferir que Lafone Quevedo mantuvo un interés duradero por el günün a iajüch. Por un lado, en 1896, en el marco de su trabajo en el Museo de La Plata, se entrevistó con un hablante de la lengua con quien elicitó un conjunto de enunciados que permaneció inédito entre sus papeles de trabajo. Luego compuso un vocabulario comparado, que por datos internos del texto puede situarse en 1898, en el que compila los datos léxico-gramaticales que había registrado junto con los relevados en otras fuentes anotadas en los siglos XVIII y XIX ${ }^{3}$. En la

1. Nuestra investigación se enmarca en el marco del proyecto PICT 2015-1507 “Tecnologías de papel. Patrones para la documentación y comunicación científica en los estudios de lenguas indígenas de Patagonia y Tierra del Fuego (1860-1930)", financiado por la Agencia Nacional de Promoción Científica y Tecnológica y radicado entre 2017-2020 en la Universidad Nacional de Río Negro.

2. En fuentes posteriores también se registran "tehuelche septentrional" y "gününa yajich" (ISO 639-3 pue). Günün a iajüch significa "Lengua de la gente"; la marca de dependencia entre 'gente' y 'lengua' se señala gramaticalmente mediante el funcional 'a'.

3. Este manuscrito fue identificado por Máximo Farro en 2014, en el curso de la catalogación del Fondo Lafone Quevedo en el archivo del Museo de La Plata. Le agradecemos nos lo haya facilitado para su análisis y publicación. 


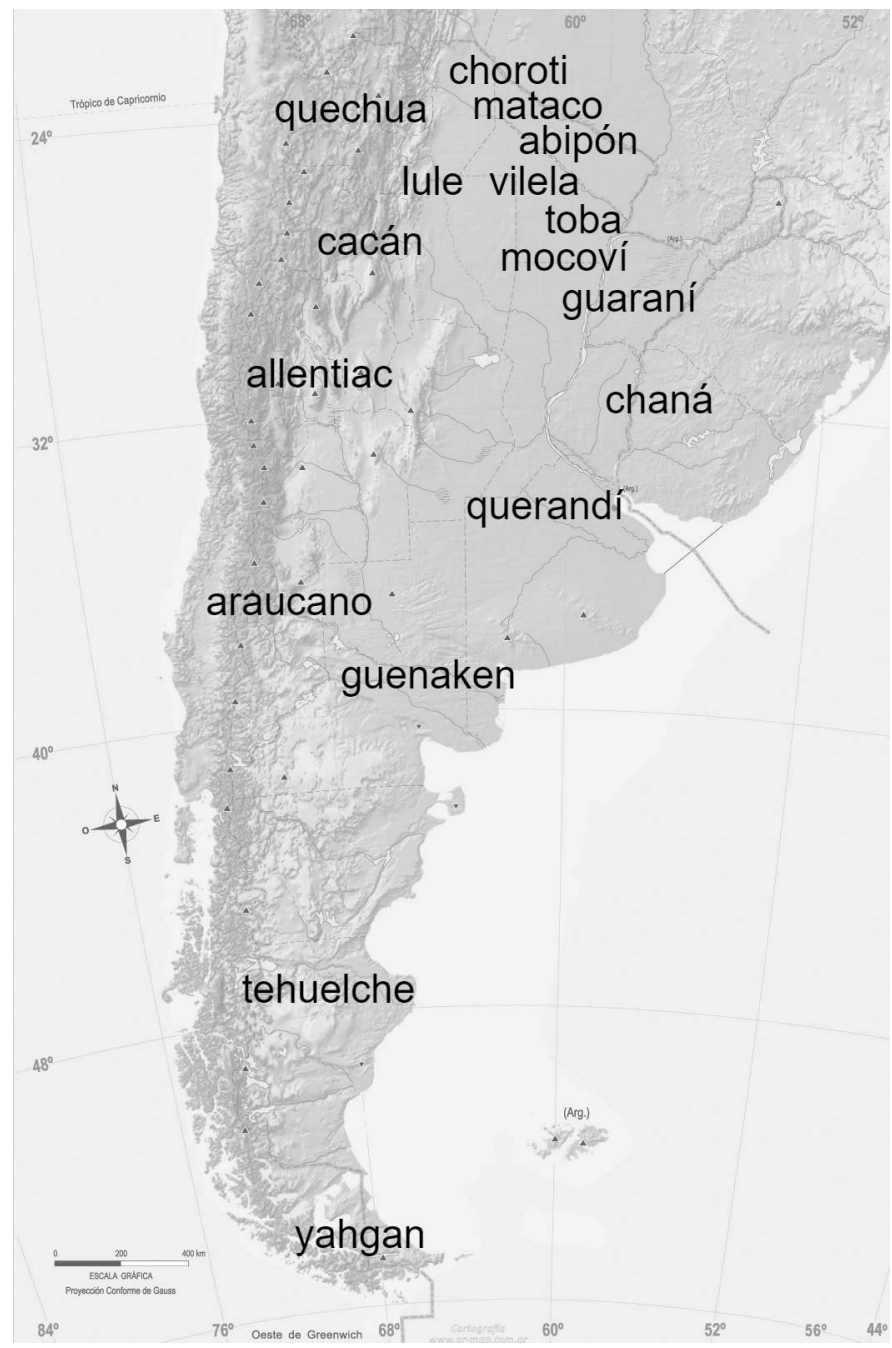

Fig. 1 - Mapa de las lenguas indígenas del territorio argentino analizadas por Lafone Quevedo, según su propia denominación

(C) formato de mapa de Creative Commons, mapa realizada por Orden, 2019).

misma época escribió un breve tratado en el que intentó establecer relaciones genéticas entre el "guenaken" y las lenguas de la familia Chon; este texto tampoco fue publicado y sólo es posible recuperar algunos fragmentos en una copia manuscrita de Bartolomé Mitre, que este autor conservó en su archivo personal. Asimismo, en distintas publicaciones y en la correspondencia de Lafone Quevedo se encuentran referencias a su interés por que se realicen 
estudios más profundos sobre la lengua, para reconocer su filiación respecto de otras variedades patagónicas ${ }^{4}$.

De este corpus, nos proponemos aquí realizar una presentación crítica de los vocabularios comparados y, en particular, recuperar la nómina original que Lafone Quevedo elicitó. A tal fin, además de describir la fuente en su materialidad, expurgamos los datos que el filólogo documenta, y analizamos la forma en que sus principales intereses e hipótesis se ponen de manifiesto tanto en su propia recolección como en la sistematización realizada. Consideramos, además, aspectos del contexto de producción de su registro, proponemos una identificación del consultante, y evaluamos las contribuciones que su recopilación realiza a los estudios actuales sobre la lengua. De este modo, además de colaborar en el incremento de los registros existentes sobre esta variedad patagónica, el análisis del manuscrito contribuye a clarificar el formato instrumental que adoptó la elicitación lingüística en la Argentina hacia fines de siglo XIX, así como a puntualizar su principal finalidad: proporcionar un acceso a la lengua que permitiera un cotejo contrastivo con la bibliografía previa y con otros registros contemporáneos.

\section{Las hipótesis lingüísticas de Lafone Quevedo}

Como señalan los diferentes autores que se han ocupado de su obra, en el periodo en que se vinculó con el MDLP Lafone Quevedo era un referente nacional en cuestiones lingüísticas. Las relaciones entabladas con destacados americanistas como Bartolomé Mitre, Vicente Fidel López, Francisco Pascasio Moreno o Manuel Trelles, así como sus vínculos con el misionero anglicano Thomas Bridges, le proporcionaron una situación privilegiada para la obtención de diversos materiales lingüísticos. Esto, como señaló Salvador Debenedetti, le permitió transitar "nuevas y desconocidas rutas hacia la solución de los complicados problemas de las afinidades de los idiomas americanos" (AAVV 1921, p. xiv). Para tal fin, además de efectuar recolecciones de datos orales, como la que referiremos, reunió una serie de documentos manuscritos y libros sobre las lenguas americanas esparcidos en colecciones privadas (Outes y Bruch 1910, p. 26). Asimismo, mantuvo un intercambio epistolar con destacados lingüistas

4. Indica por ejemplo en 1892: “¿Qué falta pues, para llenar el catálogo de las lenguas típicas de nuestro continente? El patagón, el fueguino, los idiomas de la Banda Oriental [...], y el mismo estudio que se está haciendo facilitará su clasificación" (Lafone Quevedo 1892a, p. 1). En los años siguientes expone el anhelo de que "antes que se cierre el siglo XIX [...] tengamos en letra de molde todo lo concerniente a Puelches, Tehuelches y Fueguinos" (1898d, p. vi) y que el filólogo alemán Rodolfo Lenz, radicado en Chile, ampliara sus estudios sobre mapuzugun para ofrecer "algunos datos sobre los Puelches, muy particularmente los pronombres y articulaciones de relación personal para nombres y verbos" (Lafone Quevedo 1895, p. 3). 
internacionales como Lucien Adam y Daniel Garrison Brinton, quienes destacaron su labor debido a la "escrupulosidad, la organización y la presentación metódica de la información” que Lafone Quevedo realizaba (Farro 2013, p. 535).

Lafone Quevedo compartió con Brinton la idea de que la lengua constituía un factor central en la clasificación etnológica (Imbelloni 1936). Se interesó por establecer una “"geografía histórica' de las lenguas indígenas del territorio argentino por medio de la publicación sostenida de sus trabajos y la elaboración de mapas étnico-lingüísticos donde se integraron visualmente los datos recolectados" (Farro 2013, p. 528). Su enfoque se sustenta en ciertas perspectivas del americanismo, en tanto se circunscribe al estudio de las lenguas sudamericanas y establece vínculos entre el análisis gramatical, los procesos etnohistóricos - que implicaban a menudo contacto- y los artefactos materiales y arqueológicos localizados. Esta articulación fue destacada por Boman (1922, p. 207), al observar que en su tarea docente "Lafone n'y enseigna point l'archéologie, mais la linguistique et l'ethnologie basée sur la linguistique”. Por otro lado, en su práctica Lafone Quevedo fue consecuente con su premisa de "que todo estudiante puede y debe concurrir con algo de su propia cosecha hacia el desarrollo de la lingüística americana" (Lafone Quevedo 1892a, p. 1). En tal sentido, intervino en la clarificación del complejo panorama lingüístico del territorio nacional, aportando criterios para la clasificación de las lenguas americanas. En su acercamiento, en primer lugar, priorizó la adscripción, no al tipo lingüístico (flexivo, aglutinante o aislante), sino a una modelización morfológica basada en la posición de los morfemas o clíticos pronominales en los sintagmas nominal y verbal. Esto le permitió elaborar dos esquemas típicos a los que denominó "gramáticas matrices", según la tendencia por prefijar o sufijar dichos elementos a los núcleos sintácticos:

Es costumbre de los filólogos hablar de lenguas aglutinantes, sintéticas o qué se yo; pero a mí me llamó más la atención la manera y no el hecho de la aglutinación, y desde luego establecí para mí una ley gramatical que someto a toda lengua nueva que se me presente. En tesis general, pues, parece que en nuestra América hay dos gramáticas matrices: la una que prefija sus partículas pronominales (como el Guaraní) las otras que las subfija (como el Quechua). (Lafone Quevedo 1892a, p. 1)

En la cita precedente es posible observar el posicionamiento que adopta respecto de los modelos analíticos vigentes en la época, que buscaban reconocer las tendencias a la aglutinación y polisíntesis en las lenguas del mundo ${ }^{5}$. Lafone

5. En este sentido, en el marco del análisis de las lenguas nativas americanas se distinguieron distintos agrupamientos lingüísticos basados en criterios morfológicos. Por un lado, las lenguas que tendían a la "incorporación" -según los desarrollos teóricos de von Humboldt y Steinthal, entre otros- y, por el otro, aquellas que recurrían a la "polisíntesis", hipótesis principalmente propuesta por Du Ponceau (véase al respecto una síntesis en Brinton 1886). Este tipo de análisis no se limitaba a la clasificación de las gramáticas sino que se vinculaba con lo que define Gunn (2015, p. 18-19) como "filología de las razas": "a loose set of 
Quevedo señala que esas percepciones, si bien son correctas, no constituyen parámetros suficientes para la clasificación. Por ello propone ir más allá de la esquematización del tipo de fenómeno que refiere y focaliza sobre el lugar donde ocurren los mismos: en el orden de la prefijación o sufijación de los posesivos se codifica la genética de las razas del continente.

El peso relativo de este criterio en la clasificación aumentó a través de los años. En las "Instrucciones del Museo de La Plata para los colectores de vocabularios indígenas" (Lafone Quevedo 1892b) Lafone Quevedo solicitaba que se documentaran expresiones posesivas en las frases nominales ("mi cara, tu cara, su cara [de él]", etc.) haciendo especial hincapié en observar "si la forma que se da es universal, o si las partículas agregadas varían según la palabra"; y, si se detectara variación, se proporcionaran "más ejemplos con voces que signifiquen partes del cuerpo, porque así se comprenderá mejor la regla del caso” (ibid., p. 406). También sugería anotar la formulación de las referencias pronominales personales en la frase verbal transitiva ${ }^{6}$. Aplicó luego el mismo razonamiento en los vocabularios de 1898 que aquí analizamos, y posteriormente también en los cotejos efectuados entre varias lenguas del Chaco (mocoví, toba nocten y wichi vejoz) y el quechua (Lafone Quevedo 1912). En línea con los análisis lingüísticos de sus contemporáneos, en su desarrollo conceptual insistió en que, más que guiarse por la afinidad de cognados léxicos, las clasificaciones debían priorizar el parámetro exhibido en el plano de la gramática:

We arrive to this conclusion: that we are justified in classifying some most considerable South American stocks linguistically by their pronouns, ignoring wholly or in part their vocabularies or other ethnic affinities. (Lafone Quevedo 1912, p. 5)

Por otro lado, postuló que morfemas formalmente similares constituían un elemento compartido por distintas lenguas sudamericanas:

My starting point was that the I or Y of the 1st person in all their combination with strengthening particles, and it soon became evident that they gave us the key note to most of the tongues in this part of our American Continent. (Lafone Quevedo 1912,p. 4)

Precisamente el günün a iajüch le permitirá corroborar esta segunda afirmación, dado que en la codificación de las personas se observan los fonemas que el autor destaca como recurrentes: $y$ - en la primera persona, $m$ - en la segunda. Esto lo

theoretical propositions and analytical practices for the comparison of Indian vocabularies and grammars that was informed by the methods of comparative anatomy and touted by its proponents as a scholarly method that promised unprecedented insight into questions concerning Native American origins and the phenomenon of human diversity more broadly".

6. Por ejemplo, en expresiones como "yo te quiero", "yo lo quiero", "él os quiere", y también en otros verbos: "se puede hacer con dar y castigar, lo que se ha hecho con el verbo querer" (Lafone Quevedo 1892b, p. 408). 
lleva a postular que "los dialectos Tehuelche, nuevo y viejo, septentrional y meridional, Ona, Guenaken, etc. son todos modificaciones serias de una sola lengua [...]. Lo único que parece que queda inconmovible son las articulaciones pronominales de $1^{\mathrm{a}}$. y 2a. persona" (Lafone Quevedo 1900, p. 122). "A pesar de las serias diferencias léxicas", observa entonces como indudable la semejanza entre el tehuelche y el günün a iajüch, y postula además que "algo muy remoto tienen en común las lenguas patagónicas con la Araucana”, sobre la base de otro parámetro gramatical compartido, como es el número dual (ibid., p. 122-123).

Como puede observarse, la correspondencia pronominal le ofreció a Lafone Quevedo pistas interpretativas para establecer relaciones entre las lenguas de la Patagonia, pero ellas se basaron principalmente en la intuición y en un cotejo de datos restringido en categorías y acotado a las gramáticas disponibles en ese momento. Por otro lado, la diversificación de sus estudios y el estado de inédito de muchos de sus trabajos llevó posteriormente a afirmar que Lafone Quevedo no escribió ninguna "obra fundamental o doctrinaria de conjunto" y que sus trabajos se basan en criterios empíricos y un método vacilante (Rojas 1960 [1917], p. 147). Si se observa el conjunto de materiales inéditos, las plantillas de recolección y el esquema analítico-comparativo del autor presentado, se deduce por el contrario que Lafone Quevedo presentó una metodología coherente y con objetivos claros, aunque los resultados definitivos de su propuesta de análisis no fueran expuestos en un único tratado.

\section{La composición del vocabulario}

\section{Aspectos de su materialidad}

En lo que sigue nos proponemos reconstruir el vocabulario que Lafone Quevedo documentó en 1896 -en tanto actualmente es incierto el paradero de su manuscrito original-, para luego explicar su trabajo de cotejo con otras fuentes realizado dos años más tarde en el ámbito de su gabinete.

Para ello describiremos en primer lugar los manuscritos titulados "Vocabulario Puelche-Guenaken, base el de Lafone Quevedo 1896" y "Vocabulario GuenakenEspañol", que comprenden 12 y 15 fojas respectivamente (archivo del Museo de La Plata, Fondo Lafone Quevedo, Carpeta 42, Manuscritos 9 y 10). Los mismos fueron transcriptos por el propio Lafone Quevedo en hojas cuadriculadas, luego encarpetadas y con una encuadernación cosida en forma manual. Este formato se identifica como propio de la etapa final del trabajo de elaboración lingüística que realiza también para otras lenguas (Farro 2013, p. 537).

El orden consistente de ambos manuscritos y las pocas enmiendas que se observan permiten inferir ese estatus de versión avanzada o final. De todos modos, es posible observar el carácter procesual en los documentos: existen espacios en blanco entre agrupamientos alfabéticos de palabras donde podrían 
La documentación de las lenguas patagónicas en el gabinete de Lafone Quevedo

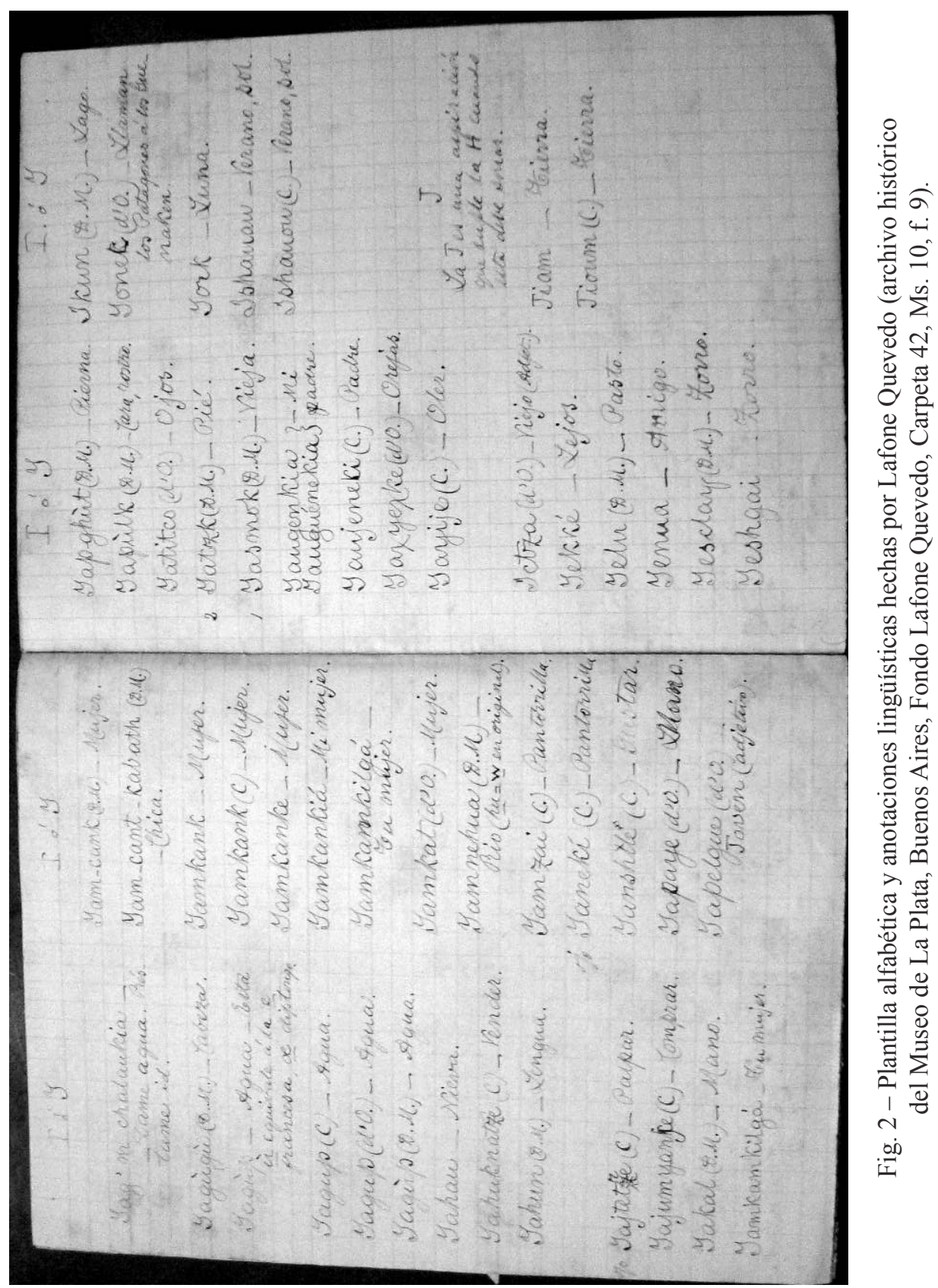


posteriormente incluirse nuevos datos, y también se observan inserciones interlineales de elementos léxicos o aclaraciones. El Manuscrito 9 presenta una variación en el uso de sucesivas tintas negras o azules ${ }^{7}$ y un mayor número de enmiendas que el Manuscrito 10. Por su parte, en este último se pone de manifiesto una calidad de tinta azul homogénea, y se incorporan en tinta negra sólo las palabras tomadas de la obra del jesuita Thomas Falkner en su Descripción de la Patagonia publicada en inglés en $1774^{8}$. Además en el Manuscrito 10 se incluyen numerosos comentarios analíticos sobre fonética y morfología, lo cual nos lleva a sostener que ambos manuscritos representan distintos momentos en el trabajo de gabinete: el primero es de reconocimiento y reescritura de los datos accesibles, mientras que el segundo sienta las bases analíticas del estudio lingüístico que emprendió Lafone Quevedo.

Por otro lado, se observa que ambos vocabularios se presentan en orden alfabético. Este tipo de plantilla era usual en otras recopilaciones sobre lenguas patagónicas realizadas desde el MDLP, como las ya mencionadas de Moreno, Burmeister o Carlos Ameghino. Sin embargo, en esos casos sólo se proponen vocabularios unidireccionales español-lengua amerindia. La innovación de Lafone Quevedo fue sumar la contraparte lengua amerindia-español, de modo similar a los textos misioneros jesuitas o a la sistematización de Thomas Bridges (1987 [1933]) para el léxico del yagan. Ese ordenamiento le permitió organizar el corpus de manera tal que evidenciara los fenómenos gramaticales y fonológicos que le interesaba analizar.

Por último, cabe destacar que, al margen de algunos lexemas, en el Manuscrito 10 Lafone Quevedo anota reiteradamente el comentario “ojo", probablemente para llamarse a sí mismo la atención en casos en que las fuentes proponían diferentes entradas en günün a iajüch para un mismo o distinto sentido conceptual en castellano, como se observa en las siguientes entradas:

$\begin{array}{lll}\text { (1) } & \text { Yamzai (C. })^{9} & \text { Pantorrilla } \\ & \text { Yaneki (C.) } & \text { Pantorrilla. ojo } \\ \text { (2) } & \text { Apiujek } & \text { Luna } \\ & \text { Apiujek(C.) } & \text { Luna } \\ & \text { Apiukùk(D.M.) } & \text { Sol. ojo }\end{array}$

7. El Manuscrito 9 está escrito con tinta negra hasta la letra LL y, a partir de la M, con azul, aunque se encuentran inserciones de contraste con otras fuentes en color azul en las letras D, I y L, así como en tinta negra en la M y T.

8. Recordemos que Lafone Quevedo realizó la traducción al castellano y la edición crítica de esta obra, publicada en la Argentina en 1911 (Falkner 1911).

9. Como se verá más abajo, Lafone Quevedo recopila lexemas de distintos vocabularios y denota con iniciales, a veces entre paréntesis, la referencia al documentador. En estos ejemplos, C. corresponde a Guillermo Cox y D.M. a Domenico Milanesio. 
Por otro lado, en el Manuscrito 10 se observa un comentario insertado por Lehmann-Nitsche, en el que este autor indica una errata y un posible reordenamiento del lexema 'veinte' bajo otra inicial (ver nota "Póngase bajo la letra P!" Lafone Quevedo 1898b, Ms. 10, f. $5^{10}$ ). Esta intervención denota que el antropólogo alemán accedió a estos materiales, aun cuando en sus publicaciones nunca se refiera a este corpus de datos producido por su colega del MDLP. La interacción sobre el mutuo interés en el günün a iajüch se extendió en el tiempo y, así, se observa en sendas cartas que en 1915 y 1916 LehmannNitsche le envió a Lafone Quevedo desde el Territorio Nacional de Río Negro, en las que le transmitía su entusiasmo por haber hallado datos empíricos que despejaban dudas en las hipótesis compartidas por ambos. En las mismas se tematiza el interés por obtener datos gramaticales y por aumentar el volumen de vocabulario disponible hasta el momento, así como también de buscar la coincidencia con fuentes anteriormente documentadas ${ }^{11}$. Es sumamente llamativo que en un periodo en que los materiales manuscritos se compartían entre estudiosos, la fuente que analizamos haya permanecido ignorada en el gabinete del lingüista. Aun cuando consta que la conoció, Lehmann-Nitsche no la incorporó al cotejo con sus datos de campo, ni se refiere al documento de Lafone Quevedo en ninguno de sus análisis de gabinete sobre las lenguas "het" de la pampa argentina (Lehmann-Nitsche 1922, 1930).

\section{Circunstancias de elicitación}

Lafone Quevedo registró un total de 116 entradas, algunas de las cuales son en realidad sintagmas o frases por su estructura y sentido. El propio filólogo ofrece dos explicaciones sobre las circunstancias de elicitación. En primer lugar, indica en el tratado (Lafone Quevedo 1898c):

En julio de 1898 [sic], el Dr. Moreno, director del Museo de La Plata, me proporcionó la ocasión de conferenciar con un indio Manzanero que hablaba el idioma de los Guenaken, y de boca de él apunté los datos que se contienen en el siguiente vocabulario. (ibid., f. 9)

Posteriormente, en su publicación de 1900, señala haber documentado las palabras pechua 'guanaco' y yag'ep 'agua' -junto con sus equivalentes na y le-é del tehuelche- de la siguiente manera:

10. NDR: Todas las referencias Ms. 9 y Ms. 10 corresponden a los dos cuadernillos del manuscrito de Lafone Quevedo 1898: Ms. 9 para Lafone Quevedo 1898a y Ms. 10 para Lafone Quevedo 1898b.

11. "Estoy tomando un vocabulario muy completo y me esfuerzo en conseguir las construcciones gramaticales. [...] La novedad para todos nosotros es el hecho que, 'gente' se dice 'künü'... El dialecto que estoy apuntando coincide muy bien con el dialecto II de Hale"' (Lehmann-Nitsche 1915); "Los tehuelches de F. [Falkner] son nuestros Puelche-Pampa!!!" (Lehmann-Nitsche 1916). 


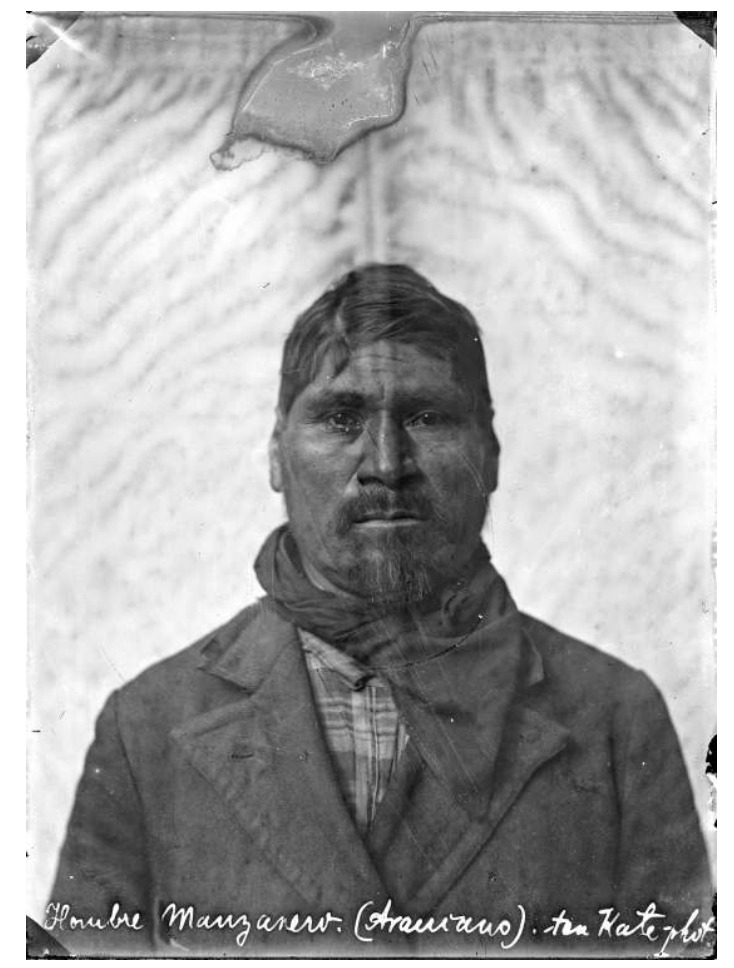

Fig. 3. Interlocutor manzanero (archivo histórico del Museo de La Plata, colección fotográfica, ARQ-002-011-0004).

Estos datos los he recogido yo mismo de la boca de indios Manzaneros, que se hallaban en el Museo de La Plata, huéspedes del doctor Moreno. (Lafone Quevedo 1900, p. 37)

Las citas permiten entrever que el interés por las lenguas patagónicas, y más precisamente por el idioma "guenaken", si no inducido fue probablemente incitado por los afanes documentales de Moreno y posibilitado por la presencia de hablantes nativos en el ámbito de la institución. En "Matériaux pour servir à l'anthropologie des Indiens de la République Argentine" (1906), Herman F.C. ten Kate refiere que en el mes de junio de 1896 tomó medidas antropométricas y fotografió a un hombre adulto referido como "l'un des amis de Rufino de la tribu des Manzaneros" que se acercó al Museo con Rufino Vera, antiguo intérprete de Inacayal y guía en distintas expediciones del MDLP, y su hija, a partir de una convocatoria realizada por Moreno. El grupo que se acercó a la institución en esa ocasión era en realidad más numeroso, y estaba compuesto por personas mapuche radicadas en La Plata y Buenos Aires, algunos de los 
cuales cumplían funciones en las fuerzas militares, policiales y los bomberos, o bien como jornaleros (Kate 1906, p. 52). No obstante, solamente ellos tres (Rufino Vera, su hija y el hombre acompañante) accedieron a realizar la prueba a cargo de ten Kate, y es debido a esta situación que se conocen algunos datos acerca de quien enunció el vocabulario. En la publicación se lo designa como "Manzanero" y "Manzanero (Araucan)" y se indican su género, su edad de entre 42 y 45 años y sus características fisonómicas (ibid., p. 52-54; véase también plancha fotográfica $6^{12}$ ). En cambio, en los manuscritos, Lafone Quevedo no registró aspectos de su trayectoria biográfica o de su dominio lingüístico. Sobre la base del apelativo, hipotetizamos su origen patagónico y su pertenencia a este colectivo socioétnico del noroeste de la Patagonia, vinculado con la gente de Sayhueque, Foyel e Inacayal (quienes en esos años ya no se encontraban deportados en el Museo). Este grupo se caracterizaba, además, por el empleo del bilingüismo mapuzungun-günun a iajüch, al que en muchos casos también sumaban conocimiento del castellano.

\section{El vocabulario registrado}

Reproducimos a continuación la nómina que Lafone Quevedo elicitó, a partir de los enunciados que se registran en ambos vocabularios manuscritos: Castellano-Guenaken y Puelche Guenaken-Castellano. Salvo indicación contraria, explicada en nota al pie, todas las expresiones se listan en ambos documentos, en distinto orden, debido a que se organizan respectivamente, sobre la base del castellano y el günün a iajüch ${ }^{13}$. En los casos en que aparecen dos variantes, aclaramos en cuál manuscrito se encuentran. La nómina comprende el siguiente corpus léxico y de frases ${ }^{14}$ :

\begin{tabular}{|l|l|l|}
\hline 1 & Agua & ${\text { yag'ep, } \text { yagù }^{15}}$ \\
\hline 2 & Agua dame & yag'm chalumkia \\
\hline 3 & Allí & koshná \\
\hline 4 & Amigo & yenua \\
\hline
\end{tabular}

12. La imagen también fue reproducida por Vignati (1942, lámina XXVIII) con el epígrafe "manzanero araucano". Para un análisis de las colecciones fotográficas a fines del siglo XIX en el Museo de La Plata véase Farro (2012).

13. La publicación completa de ambos manuscritos se encuentra actualmente en preparación a cargo de las autoras de este artículo.

14. Mantenemos en la transcripción los grafemas y diacríticos propuestos por el autor; nuestra única intervención consistió en reubicar en orden alfabético algunos pocos lexemas respecto del original y consignar el orden numérico aquí expuesto. Colocamos entre paréntesis las fojas correspondientes de los lexemas en los dos vocabularios.

15. La primera forma aparece en ambos vocabularios (Ms. 9, f. 1; Ms. 10, f. 10) y la segunda sólo en Ms. 10, f. 10. 


\begin{tabular}{|c|c|c|}
\hline 5 & Anda (¿Cómo anda?) & keshmen pahante \\
\hline 6 & Aquí & huat'n \\
\hline 7 & Armadillo & heikman \\
\hline 8 & Avestruz & gai \\
\hline 9 & Barba (pelo) & hupelgues \\
\hline 10 & Barriga & huetetr \\
\hline 11 & Bebo & chokek \\
\hline 12 & Boca & huepetk \\
\hline 13 & Brazo & aschcap \\
\hline 14 & Bueno & attke \\
\hline 15 & Cabeza & agehe, aguehe \\
\hline 16 & Tu cabeza & agehelga \\
\hline 17 & Calor & getsé, getsè $^{16}$ \\
\hline 18 & Canilla & ayaúgùs \\
\hline 19 & Cara & apk \\
\hline 20 & Mi cara & huipk \\
\hline 21 & Carne & pichua \\
\hline 22 & Cinco & tanke \\
\hline 23 & Comer & guelmepenke, gelmeken'ke \\
\hline 24 & Como & chokeknek \\
\hline 25 & Corazón & tsaju \\
\hline 26 & Cuatro & mal-l-(e) \\
\hline 27 & Cuero & lejlùk \\
\hline 28 & Dame agua & yag'm chalaukía \\
\hline 29 & Día & amáha \\
\hline 30 & Diente & ahái \\
\hline 31 & Dientes & ojaiue \\
\hline 32 & Dientes (mis) & huaikia \\
\hline 33 & Diez & zamatske \\
\hline 34 & Dormir (yo), duermo & chukuplauke \\
\hline 35 & Dos & pech \\
\hline 36 & Esta casa es mía & huasa-ahuay-kia \\
\hline 37 & Estrella & t'se'selk \\
\hline 38 & Fuego & aguakek \\
\hline 39 & Guanaco & pechua \\
\hline 40 & Hablo & chujesealk \\
\hline 41 & Hembra & ayehesiluche \\
\hline 42 & Hermana & ugupatzum \\
\hline 43 & Hermana (tuya?) & uguepatsum \\
\hline 44 & Hermano & ukkūne \\
\hline
\end{tabular}

16. El primer lexema aparece en Ms. 9, f. 2 y el segundo en Ms. 10, f. 8. 
La documentación de las lenguas patagónicas en el gabinete de Lafone Quevedo

\begin{tabular}{|c|c|c|}
\hline 45 & Hermano (mío) & ukenkia \\
\hline 46 & Hija (mia) & zegankia \\
\hline 47 & Hijo & agatrki \\
\hline 48 & Hijo (mio) & agatschkia \\
\hline 49 & Hombre & kenna \\
\hline 50 & Hombre & pastrey \\
\hline 51 & Invierno & mágguin, magguin $^{17}$ \\
\hline 52 & Lejos & yekke, yekké18 \\
\hline 53 & Laguna & ek'ken \\
\hline 54 & Lengua & aónak, aunùk \\
\hline 55 & Lengua (mía) & aunùkya \\
\hline 56 & León & haina \\
\hline 57 & Luna & appioj, apiujek \\
\hline 58 & Luna & york \\
\hline 59 & Llanura & chalach \\
\hline 60 & Lluvia & zenána \\
\hline 61 & Macho & kamaia \\
\hline 62 & Madre mía, mi madre ${ }^{19}$ & mamakia \\
\hline 63 & Mano & aágallk, aagallk ${ }^{20}$ \\
\hline 64 & Más mejor & kette-sasse ${ }^{21}$, kette attke \\
\hline 65 & Matar & chauban \\
\hline 66 & Mia & kia (subfijo), $y a^{22}$ \\
\hline 67 & Mocetón & pastrai \\
\hline 68 & Muchacho & agatr \\
\hline 69 & Muera (yo) & chajkam \\
\hline 70 & Mujer & yamkank, yamkanke \\
\hline 71 & Mujer mía & yamkankia \\
\hline 72 & Mujer tuya & yamkankilgá \\
\hline 73 & Narices (mis/mía) & huinetr \\
\hline 74 & Nieva & yahau \\
\hline 75 & No & kanéu \\
\hline 76 & Noche & trùmu, tchemen \\
\hline 77 & Nueve & tchiiba \\
\hline 78 & Ocho & porsa \\
\hline
\end{tabular}

17. El término lleva tilde en el Ms. 9, f. 6 y carece de ella en Ms. 10, f. 12.

18. El término lleva tilde sólo en el Ms. 10, f. 10 y carece de ella en Ms. 9, f. 7.

19. La primera expresión en Ms. 9, f. 7, y la segunda en Ms. 10, f. 12.

20. El término lleva tilde en el Ms. 9, f. 7 y carece de ella en Ms. 10, f. 2.

21. El guión intermedio en la primera expresión aparece sólo en el Ms. 10, f. 10; no así en Ms. 9, f. 7.

22. La primera forma en el Ms. 9, f. 8; la segunda, en Ms. 10, f. 8. 
Marisa Malvestitti y María Emilia Orden

\begin{tabular}{|c|c|c|}
\hline 79 & Ojos & atetk \\
\hline 80 & Ojos (tus) & huitetkelga ${ }^{23}$ \\
\hline 81 & Once & zamatske-chia \\
\hline 82 & Oreja & atshke \\
\hline 83 & Orejas & huitzesk \\
\hline 84 & Orines & attesk \\
\hline 85 & Padre (mi) & $\begin{array}{l}\text { yaugen-kia, yauguenkia, } \\
\text { llauguen-kia }\end{array}$ \\
\hline 86 & Padre (tu) & llauguen-elga \\
\hline 87 & Padre (su) & kosian-guenka \\
\hline 88 & Perro & dash'a \\
\hline 89 & Pié & atsk \\
\hline 90 & Pié (mi) & huetzk \\
\hline 91 & Piedra & tchiye \\
\hline 92 & Pierna & attgp \\
\hline 93 & Prestar & chalau \\
\hline 94 & Préstame & chalaukia \\
\hline 95 & Río & arskatch \\
\hline 96 & Seis & tremman \\
\hline 97 & $\mathrm{Si}$ & $a^{\prime} a$ \\
\hline 98 & Sierra & atek \\
\hline 99 & Siete & katchpitch \\
\hline 100 & Sol & amáha, ishauau ${ }^{24}$ \\
\hline 101 & Suri & gai \\
\hline 102 & Tierra & jiam \\
\hline 103 & Tío mio & apgézekiá \\
\hline 104 & Toldo (casa) & ahuay \\
\hline 105 & Tres & guettrh \\
\hline 106 & Tú, tus & elga, ilga (subfijo $)^{25}$ \\
\hline 107 & Uno & chi \\
\hline 108 & Uña & huepas \\
\hline 109 & Veinte & petcha-zamaske \\
\hline 110 & Venas & atchichi \\
\hline 111 & Verano & ishauau $^{26}$ \\
\hline 112 & Viento & eyiyi \\
\hline 113 & Vosotros & kùman \\
\hline 114 & Vulva & arski \\
\hline 115 & Yo & kioua \\
\hline 116 & Zorro & yeshgai \\
\hline
\end{tabular}

23. Esta forma posesiva sólo se registra en el Ms. 9, f. 9. 
La documentación de las lenguas patagónicas en el gabinete de Lafone Quevedo

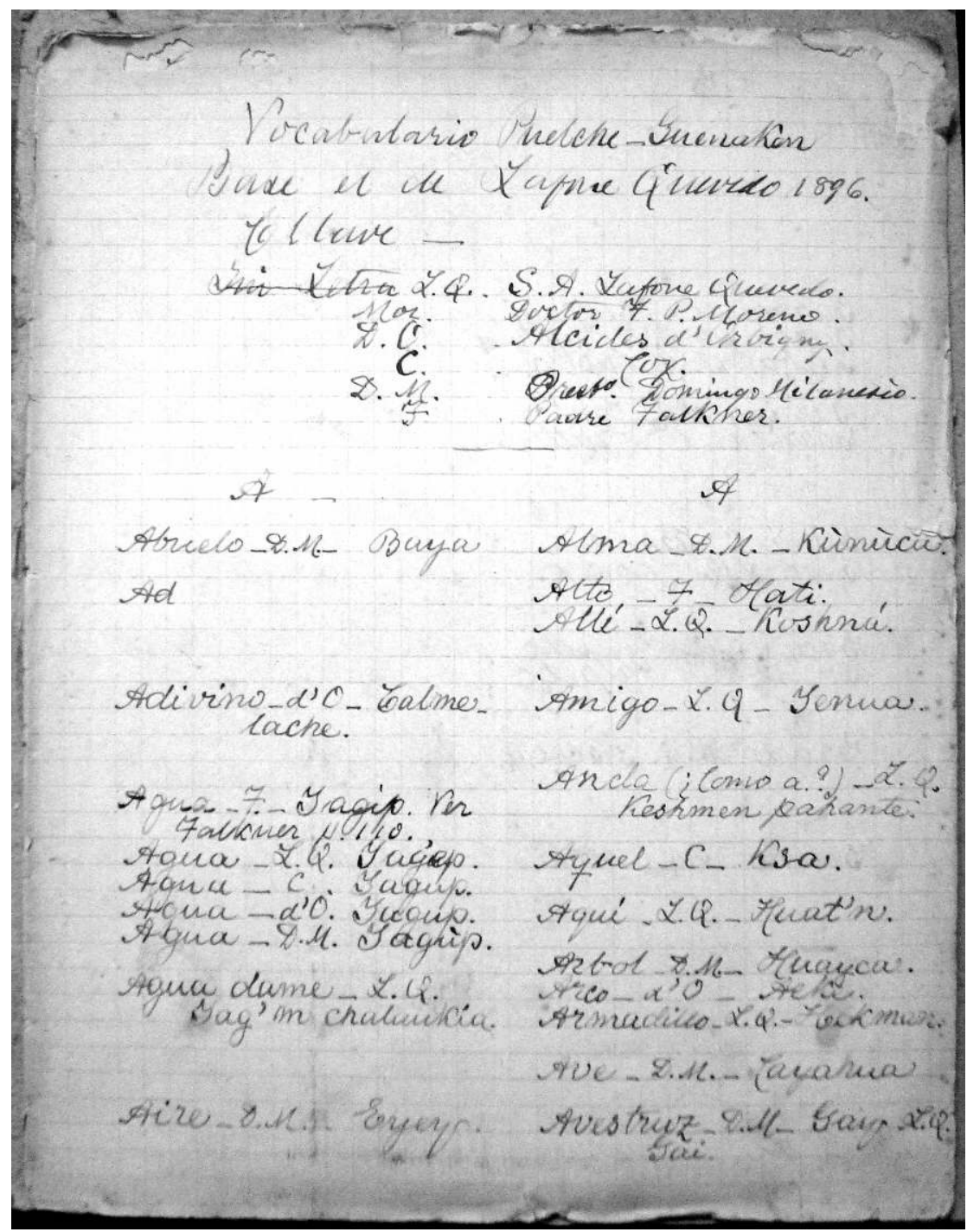

Fig. 4 - Estrategia de cotejo

(archivo histórico del Museo de La Plata, Buenos Aires,

Fondo Lafone Quevedo, Carpeta 42, Ms. 9, f. 1).

24. Ambos términos aparecen secuenciados en Ms. 9, f. 11. El primero también en Ms. 10, f. 3 con el mismo sentido; el segundo, en Ms. 10, f. 10 como equivalente de 'verano'.

25. Esta forma posesiva solo se registra en el Ms. 9, f. 11.

26. 'Verano' como equivalente sólo se registra en el Ms. 10, f. 10. 
Entre los lexemas que anota Lafone Quevedo se destacan varias expresiones que preconizaba recopilar en las Instrucciones. Registra así denominaciones en günün a iajüch para partes del cuerpo humano, términos de parentesco y expresiones de uso cotidiano, y provee los equivalentes del sustantivo 'agua', de verbos ('dar', 'prestar', 'beber' 'comer', 'dormir', 'matar') y de otras categorías gramaticales ('sí', 'no', 'allí', 'aquí'), junto con pronombres personales y posesivos aplicados a los elementos corporales. Se destaca además en la nómina presentada que una cuarta parte de los lexemas de los que solicita equivalencia ('agua', 'barba', 'boca', 'cabeza', 'dientes', 'estrella', 'fuego', 'hombre', ‘yo', 'lengua', 'luna', 'mano', 'narices', 'ojos', ‘oreja', ‘pie', ‘pierna', 'río', 'tierra', 'sol', 'vosotros') también se presenta en el cuadro comparativo en el que contrasta ejemplos de lenguas del Chaco a fin de clasificar, como mencionamos antes, los agrupamientos lingüísticos sudamericanos (Lafone Quevedo 1912). Por último, en sintonía con un campo conceptual generalmente recopilado en las documentaciones coloniales de la época, registra los numerales del uno al diez y el veinte. Todo ello constituye un claro indicador de que Lafone Quevedo recoge las expresiones en günün a iajüch de acuerdo con una sistematización que no aleatoria sino con base en un instrumento ordenado alfabéticamente y previamente estandarizado.

Aun cuando se trate de una lista corta, adecuada a una situación de elicitación temporalmente acotada, queda en evidencia que la bibliografía anterior -que expondremos en el apartado siguiente-constituye la guía para este listado, en tanto Lafone Quevedo intentaba chequear con su registro muchos lexemas anteriormente documentados. En cuanto al registro naturalista, en la nómina que reconstruimos se observa que anota nombres de la fauna patagónica como 'armadillo', 'avestruz', 'guanaco'; elementos naturales de la región, como 'montaña', 'llanura', 'sierra', 'nieve' y ‘viento'; además de referentes culturales, como 'toldo' y 'cuero'. Entre las denominaciones corporales, incorpora los términos arski 'vulva' y attesk 'orines', no atestados en otros registros previos de la lengua. Por último, también enuncia algunas expresiones emergentes del marco conversacional informal, como por ejemplo: 'cómo anda', 'más mejor', 'dame agua' y 'préstame', integrando en estas últimas las referencias pronominales que buscaba relevar.

\section{Los vocabularios comparados}

Tiempo después, Lafone Quevedo decidió volcar en otro instrumento los datos recolectados en esta instancia en el MDLP, junto con otros registros sobre el günün a iajüch de los que disponía. De este modo compiló 339 entradas alfabéticas en los dos manuscritos que arriba presentamos -lo que no implica ese mismo número de palabras, ya que en varios casos se recogen diversos registros de un mismo término. 
Desde las primeras menciones de la lengua hechas por los jesuitas en el siglo XVIII en adelante, la documentación sobre el günün a iajüch presentó relevamientos fragmentarios, que el mundo académico recuperó sistemática y recursivamente (Orden 2017). Lafone Quevedo cita en la portada de ambos textos, bajo el título "Clave", las fuentes léxicas que consideró para la elaboración de sus dos vocabularios integrados: Thomas Falkner (1774), Alcide d'Orbigny (1839), Guillermo Cox (1863), Domenico Milanesio (1898), y los apuntes entonces inéditos de Francisco Moreno $^{27}$, además de su propia muestra. La referencia a las fuentes consultadas nos permite datar su cotejo como posterior a la publicación, en 1898, del texto de Milanesio en Buenos Aires. Además, cuando en abril de 1898 Lafone Quevedo presentó su trabajo "La raza pampeana y la raza guaraní" en el Congreso Científico Latinoamericano, informaba haberse basado en los datos de d'Orbigny, Cox, Moreno y sus propios apuntes (Lafone Quevedo 1900, p. 107), sin mencionar aún la recopilación efectuada por el salesiano.

De Cox y Milanesio copió toda la nómina de lexemas (65 en el caso de Cox y 64 en Milanesio, además en este último caso, de los numerales), mientras que de Moreno sólo transcribió tres pronombres (tú, él, nosotros), de Falkner cinco nominales (los sustantivos guanaco, agua, sierra y abrevadero y el adjetivo alto) y de d'Orbigny treinta y cuatro términos (básicamente sustantivos, pronombres y algunos verbos) que el viajero francés había publicado ${ }^{28}$. De este modo, sus propios datos de campo se cotejaron con los de otros cinco registros: algunos temporalmente disímiles (del siglo XVIII y de principios y mediados del siglo XIX) y otros contemporáneos, que habían sido tomados en lugares diversos como Sierra de los Padres, Carmen de Patagones, meseta de Somuncura y precordillera de los Andes ${ }^{29}$.

La preeminencia que asignaba a las recopilaciones de Cox y Milanesio se explica porque estas documentaciones, además de ser cercanas temporalmente, también habían sido anotadas en interacciones con hablantes de procedencia manzanera y norpatagónica, tanto en la región neuquina recorrida por Cox como

27. Durante su viaje a Norpatagonia en 1873, Moreno (1876) reporta haber interactuado con distintas personas hablantes de günün a iajüch y haber confeccionado un vocabulario. Del mismo sólo se conservan actualmente dos páginas manuscritas en el Museo Mitre de Buenos Aires, publicadas en 1909, como indicamos antes, en el Catálogo razonado... de ese autor.

28. Lafone Quevedo accedió a los materiales lingüísticos del cuadro publicado en el Tomo IV de Voyage dans l'Amérique méridionale (Orbigny 1839, p. 80). La documentación completa de d'Orbigny fue publicada recién en 1902 por Raoul de La Grasserie.

29. En cambio, no hay indicios de que el autor haya consultado el vocabulario y fraseario anotado por el filólogo estadounidense Horatio Hale en 1839 en Carmen de Patagones (Hale 1846), con el que contaron tanto Mitre como Lehmann-Nitsche. Tampoco informa haber dispuesto del material de Carlos Ameghino, quien entre 1887 y 1902 realizó quince viajes a la Patagonia como colaborador de su hermano Florentino (Vizcaino 2011), contexto en el que se indica que recopiló un vocabulario actualmente inhallable. 
en las reducciones posteriores a la Campaña del Desierto en donde misionaba Milanesio. Por otro lado, Lafone Quevedo utiliza un grafemario similar al de Cox para registrar sus datos, y marca el acento agudo sobre la u de modo congruente con el salesiano.

Para su cotejo, Lafone Quevedo imprimió una estrategia alfabética secuencial al vocabulario comparado. En lugar de plantear una distribución de los lexemas en columnas paralelas, cada una correspondiente a una lengua o a un recopilador, que era el formato más usual en el ámbito nacional, realizó una enunciación consecutiva de las distintas entradas de una misma palabra, que extrapoló de sus fuentes. Este formato paratextual recuerda el utilizado posteriormente por Lehmann-Nitsche en su bien conocida obra acerca de las lenguas chon (1913), aunque el trabajo de Lafone Quevedo se diferencia de éste en tanto no reúne los lexemas por categorías (sustantivos, adjetivos, verbos, etc.) ni por campos semánticos.

\section{Aportes de la recopilación y la sistematización de Lafone Quevedo al conocimiento del günün a iajüch}

A continuación ofrecemos una descripción de los datos lingüísticos que provee el vocabulario anotado por Lafone Quevedo, así como los comentarios metalingüísticos que incluye, enfatizando su relevancia para los estudios lingüísticos actuales. Observamos, además, en qué medida los mismos están sesgados por los problemas lingüísticos que le interesaban y por los distintos niveles de análisis involucrados en su estudio.

\section{Nivel fonético-fonológico}

Como mencionamos, el grafemario empleado es congruente con el de Guillermo Cox. Lafone Quevedo incluye en el mismo las vocales a, e, i, o, u y las consonantes b, c, ch, d, g, h, j, k, kk, 1, 1l, m, n, p, s, t, tz, z. Se preocupa además por mantener coherencia en este plano, y por ello, en comentarios expone la reformulación realizada respecto de la transcripción original de la fuente, como por ejemplo: "En D.M. hu=w del original." (Ms. 10, f. 3).

\begin{tabular}{|l|l|}
\hline \multicolumn{1}{|c|}{$\begin{array}{c}\text { Sistema fonológico } \\
\text { (reconstruido en Orden 2017) }\end{array}$} & \multicolumn{1}{c|}{$\begin{array}{c}\text { Grafemario utilizado } \\
\text { por Lafone Quevedo }\end{array}$} \\
\hline p- oclusiva bilabial sorda & $\mathrm{p}$ \\
\hline t- oclusiva dental sorda & $\mathrm{t}$ \\
\hline k- oclusiva velar sorda & $\mathrm{k}$ \\
\hline b- oclusiva bilabial sonora & $\mathrm{b}$ \\
\hline d- oclusiva dental sonora & $\mathrm{d}$ \\
\hline g- oclusiva velar sonora & $\mathrm{g}$ \\
\hline tI- africada ápico prepalatal sorda & $\mathrm{tr}$, thr \\
\hline
\end{tabular}


La documentación de las lenguas patagónicas en el gabinete de Lafone Quevedo

\begin{tabular}{|l|l|}
\hline t $\int$ - africada dorso prepalatal sorda & ch \\
\hline ş- fricativa ápico prepalatal sorda & $\mathrm{s}, \mathrm{z}$ \\
\hline x- fricativa dorso velar sorda & $\mathrm{h}, \mathrm{j}, \mathrm{x}$ \\
\hline P- oclusiva glotal & $\mathrm{r}$ \\
\hline m- nasal bilabial sonora & $\mathrm{m}$ \\
\hline n- nasal dental sonora & $\mathrm{n}$ \\
\hline r- vibrante dental sonora & $\mathrm{r}$ \\
\hline 1- lateral ápico prepalatal sonora & $\mathrm{l}$ \\
\hline 1- lateral ápico prepalatal sorda & $\mathrm{pl}$ \\
\hline j- semiconsonante palatal sonora & $\mathrm{y}$ \\
\hline w- semiconsonante labiovelar sonora & $\mathrm{hu}, \mathrm{o}, \mathrm{u}, \mathrm{w}$ \\
\hline i- anterior alta cerrada & $\mathrm{i}$ \\
\hline ü- central alta cerrada & $\mathrm{u}$ \\
\hline u- posterior alta cerrada & $\mathrm{u}$ \\
\hline e- media anterior & $\mathrm{e}$ \\
\hline a- central baja abierta & $\mathrm{a}$ \\
\hline
\end{tabular}

Fig. 5 - Fonemas de la lengua y grafemas correspondientes en los vocabularios elicitados por Lafone Quevedo (Orden 2017).

Para tratar de transcribir fonemas del günün a iajüch inexistentes en castellano, recurre a dos estrategias. Por un lado, ofrece en algunos casos una breve descripción en la que propone un paralelo con los fonemas de lenguas europeas ("La $\overline{\mathrm{u}}$ es la e francesa" [Ms. 10, f. 13]; "u inglesa como en tuck" [Ms. 10, f. 11]; "rs = x catalana" [Ms. 9, f. 9]), y en otros, recurre al mapudungun para marcar la similitud fónica ("La Tr o Thr es más o menos la Th del Araucano" [Ms. 10, f. 12]).

Por otro lado, como anticipamos, en la versión Guenaken-castellano, proporciona algunos comentarios metalingüísticos en los que efectúa observaciones articulatorias acerca de fonos que presentan procesos de aspiración - "la J es una aspiración que suple la H cuando esta debe sonar" (Ms. 10, f. 9); "la X es más bien como la $\mathrm{S}$ gruesa, como en Catalán. Como H ver Haina" (Ms. 10, f. 13)- y glotalización - "La K es una C dura o Qu ante E o I. En realidad, son una sola letra" (Ms. 10, f. 10). Además, refleja los procesos de glotalización en la oclusiva velar al interior de palabra, representándolos gráficamente con la duplicación del grafema (3) y el uso de una comilla simple (4):

$\begin{array}{lll}\text { (3) } & \text { Lejos } & \text { yekke } \\ & \text { Invierno } & \text { mágguin } \\ \text { (4) } & \text { Laguna } & \text { ek'ken } \\ \text { Estrella } & \text { t'se'selk }\end{array}$


También ofrece un ejemplo de geminación de la palatal en interior de palabra, representada a través de la separación de /1/ mediante guiones: ma-1-1-e 'cuatro' . Esta diferenciación aporta al reconocimiento de un proceso de palatalización en marcha en el sistema del günün a iajüch, principalmente visible para la posición final de palabra como cuando transcribe, por ejemplo, aágallk: 'mano'.

En cuanto a las vocales, en frases sencillas y en ciertos lexemas también hay pistas fonéticas sobre su elisión o brevedad (principalmente de la central alta cerrada $/ \ddot{\mathrm{u}} /$ ) en el contexto de palabras (5) y frases (6):

$\begin{array}{ll}\text { (5) Aquí } & \text { huat'n } \\ & \text { watün } \\ \text { 'aquí' } \\ \text { (6) Dame agua } & \text { yag'm chalaukia } \\ & \text { yagüp mü-cha-taw-kja }{ }^{30} \\ & \text { agua MI.2.SG-A-dar-1.SG }{ }^{31} \\ & \text { 'agua dame' }\end{array}$

A nivel suprasegmental, el autor emplea dos tipos de tildes: el acento agudo (') y el grave ('). En las fuentes por él consultadas solo es posible observar un patrón de marca suprasegmental en Milanesio, aunque el religioso sólo marca el acento agudo, como en el francés; mientras que Lafone Quevedo amplía las posibilidades. Utiliza así claramente el acento grave para marcar la tonicidad del lexema en su función culminativa (7), o bien una función demarcativa, entre nominales y sufijos (8):

$\begin{array}{ll}\text { (7) Sol } & \text { amáha } \\ \text { Lluvia } & \text { zenána } \\ \text { No } & \text { kanéu } \\ \text { (8) Tío (mío) } & \text { apgéze-kiá } \\ & \text { apgüşü-kjá } \\ & \text { tío-POS.AL.1.SG } \\ & \text { 'mi tío' }\end{array}$

30. La base verbal dar se registra en las fuentes con dos variantes: tau y lau; en las glosas lingüísticas utilizamos la primera forma.

31. Empleamos las siguientes abreviaturas gramaticales: ASP: aspectual; FUNC: funcional; FUT: futuro; INTERR: interrogativo; POS.AL: posesivo alienable; POS.INAL: posesivo inalienable; PTE: presente; MI: modo imperativo; MR: modo realis; SG: singular; 1, 2, 3: primera, segunda y tercera persona. En los ejemplos con glosas, mantenemos en la primera línea la grafía de los recopiladores según el texto de Lafone Quevedo; en la segunda, efectuamos nuestra propia transcripción fonológica y en la tercera, la segmentación gramatical. En la cuarta línea ofrecemos nuestra traducción al español. 
La documentación de las lenguas patagónicas en el gabinete de Lafone Quevedo

$\begin{array}{ll}\text { Mujer tuya } & \text { yamkankilgá } \\ & \text { yamkank-ilga } \\ & \text { mujer-Pos.AL.2.SG } \\ & \text { 'tu mujer' }\end{array}$

Las ocurrencias del acento agudo no pueden especificarse con igual precisión, aunque puede hipotetizarse que es una de las marcas para la vocal central alta cerrada /ü/ (9). En ocasiones ambos tipos de tilde coinciden o se usan alternativamente en una misma palabra (10):

\begin{tabular}{|c|c|c|}
\hline \multirow[t]{2}{*}{ (9) } & Vosotros & kùman \\
\hline & Noche & trùmu \\
\hline (10) & Canilla & ayaúgùs \\
\hline & Calor & getsé, getsè \\
\hline
\end{tabular}

En síntesis, Lafone Quevedo emplea algunos recursos grafémicos que intentan reflejar intuitivamente lo escuchado de su consultante. En especial, las distinciones suprasegmentales que establece son importantes para los estudios que abordan actualmente la descripción del sistema, en tanto se trata de una de las pocas fuentes que registran este nivel de análisis.

\section{Nivel gramatical}

Lafone Quevedo (1900, p. 123) describe acertadamente el günün a iajüch como "una lengua subfijadora de partículas de relación personal". A partir de expresiones referidas a partes del cuerpo y relaciones de parentesco, coteja, como dijimos, diferentes formas para delimitar los sufijos posesivos y de persona anexados a las bases léxicas, intuyendo tal vez la existencia de posesión inherente en el günün a iajüch. Como se observa en los ejemplos que expone en su artículo de 1900, se pregunta si "ue" (que representa el morfema de posesión inalienable para la primera persona del singular $w$-) debería coocurrir en los lexemas "cabeza" y "tu cabeza", tomados de su propio vocabulario:
(11) Cabeza
ageheue?
Tu cabeza
agehelgaue? (Lafone Quevedo 1900, p. 107)

También segmenta los sufijos posesivos en los términos de parentesco, de modo de reponer las distintas opciones morfológicas:

\begin{tabular}{|c|c|c|}
\hline \multirow[t]{4}{*}{$(12)$} & Padre mío & yaugen-kia o yauguenkia \\
\hline & Padre (mi) & llauguen-kia \\
\hline & Padre (tu) & llauguen-elga \\
\hline & Padre (su) & kosian-guenka (Ms. 9, f. 10) \\
\hline
\end{tabular}




$$
\begin{aligned}
& \text { (13) yamkankiá mi mujer } \\
& \text { yamkamkilgá tu mujer (Ms. 10, f. 8; ver Fig. 2) }
\end{aligned}
$$

En pos de este reconocimiento de los morfemas posesivos, segmenta los ítems recopilados en otras fuentes como lexemas en expresiones más complejas. Esto se observa en varios términos de Milanesio y de Cox, que Lafone Quevedo interviene separando la marca de posesivo "y" $-y a-$, y otorgando una correspondencia de persona:
Lengua (mi!)
Mi cabeza
D.M.
$y$-ahun
C. $\quad y$-agueje

Intenta además deducir de modo explícito los sentidos y funciones de prefijos y sufijos que refieren a las personas, en comentarios como los siguientes: "Javer- Kia parece ser "yo"” (Ms. 10, f. 7); “(Parece que K sea prefijo común a las tres personas lo que dejaría libre el Ja de $1^{\text {ra }}$ persona. Ver kian y kmao)" (Ms. 10, f. 10). Es decir que, aunque sin explayarse ni indicar su función, devela que la forma $k$-se añade a la marca de primera persona. Su propuesta de segmentación coincide con los análisis lingüísticos actuales de este morfema. Tal como se postula en Orden (2017), k- corresponde a un marcador de animacidad que compone tanto formas libres de pronombres personales como sufijos posesivos de alienabilidad; así, estos se segmentan: $k-w-a$ (animacidad-1 persona- singular) y $-k-j-a$ (animacidad-1 persona- singular). Por otro lado, en secuencias como la siguiente puede notarse que el autor detecta la existencia de otros afijos que intervienen en las expresiones posesivas, apelando a pares comparativos:

$\begin{array}{lll}\text { (15) Diente } & \text { L.Q. } & \text { Ahai } \\ \text { Dientes } & \text { C. } & \text { Ojaiye } \\ & \text { L.Q. } & \text { Ojaiue } \\ \text { Dientes (mis) } & \text { L.Q. } & \text { Huaikia }\end{array}$

En las tres formas documentadas por Lafone Quevedo se observan variaciones en la prefijación: el primer ejemplo corresponde a una forma genérica, mientras que los otros tres ponen de manifiesto el prefijo inalienable de primera persona $w$-. En el último término, se observa una doble afijación posesiva, que suele registrarse en fuentes del siglo xx: $w$ - (ha)i-kja; primero el prefijo de posesión inalienable, y luego el sufijo de posesión alienable. En Orden (2017) hemos explicado cómo la distinción obligatoria alienable/inalienable comenzó a atravesar un proceso de cambio, principalmente en relación con los términos referidos a partes del cuerpo y parentesco. Por ejemplo, en los registros posteriores tomados por Lehmann-Nitsche en 1915-1916 se observa una notable alternancia y múltiples posibilidades de afijación de los posesivos: 
La documentación de las lenguas patagónicas en el gabinete de Lafone Quevedo

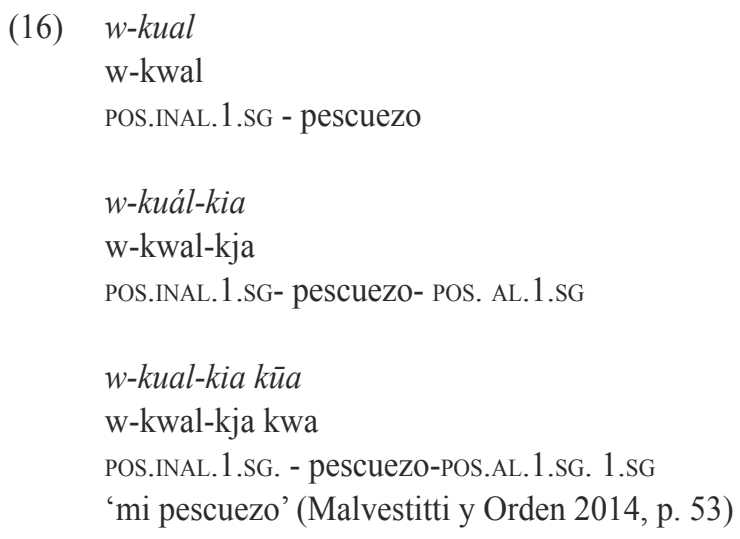

En cuanto al registro del sufijo - lga para referir a la posesión de segunda persona singular, no se evidencia en las fuentes consultadas por Lafone Quevedo aunque sí en su propio registro. También se reconoce en la documentación de campo de su colega, quien aclara que esa forma sólo corresponde al singular. Esta coincidencia de ambos relevamientos, que no se relacionaron y que fueron realizados en distintos momentos y circunstancias, nos permite confirmar la existencia de otra forma sufijada para la segunda persona del singular que alterna con el posesivo alienable de segunda persona -kma. Suponemos que posiblemente se vincule con restricciones de tratamiento (como vos/usted del castellano), o bien a su integración en una variedad dialectal denominada "manzanera", propia del contrafuerte cordillerano, con cuyos hablantes se relacionaron ambos investigadores. Respecto de la categoría de número, también se observa una búsqueda contrastiva a fin de establecer los morfemas que denotan pluralidad en la lengua. En este sentido, el autor coloca pares para constatar la existencia de marcación morfológica:

$\begin{array}{lll}\text { (17) } & \text { Oreja } & \text { atshke } \\ & \text { Orejas } & \text { huitzesk } \\ \text { (18) } & \text { Pié } & \text { atsk } \\ & \text { Pié } & \text { huetzk }\end{array}$

En este caso, si bien no reconoce entre su transcripción o sus comentarios la existencia de una marca plural $^{32}$, su corpus nos permite evidenciar el morfema -sk que constituye, según nuestra hipótesis (Orden 2017), un marcador plural de par simétrico.

32. Nótese que, en el ejemplo que reproducimos como (18), Lafone Quevedo utiliza el singular en el equivalente en castellano en lugar del transparente 'pies' para referirse al par. 
En cuanto a la marcación de género, también el vocabulario de Lafone Quevedo realiza un gran aporte, ya que registró el par léxico ayehesiluch 'hembra'/kamaia 'macho', documentado en el siglo xx por Lehmann-Nitsche (Malvestitti y Orden 2014), Tomás Harrington (s. f.) y Rodolfo Casamiquela (1983), como yewülnüch 'yegua'/kümayü 'macho'. En cuanto a la distinción gramatical, solo encontramos en su listado un término que contiene el sufijo-chum, que es el marcador para femenino en humanos, animales y seres mitológicos:

$$
\begin{array}{ll}
\text { (19) Hermana } & \text { ugupatzum } \\
\text { Hermana (tuya?) } & \text { uguepatsum }
\end{array}
$$

En relación con la frase verbal, el autor recolecta ejemplos con bases que presentan flexión de primera persona. De este modo, su corpus es similar al relevado por Cox, quien sólo atestigua esa persona gramatical. A diferencia de éste, por medio de la segmentación de los prefijos y en las glosas al castellano, Lafone Quevedo identifica que no se trata de un infinitivo sino de un verbo conjugado. Podemos apreciar así una serie de verbos activos en los que el autor destaca el uso de la primera persona, en tiempo presente con el prefijo kücha- (la elisión de la primera sílaba $k \ddot{u}$ en los ejemplos se debe a fenómenos articulatorios):

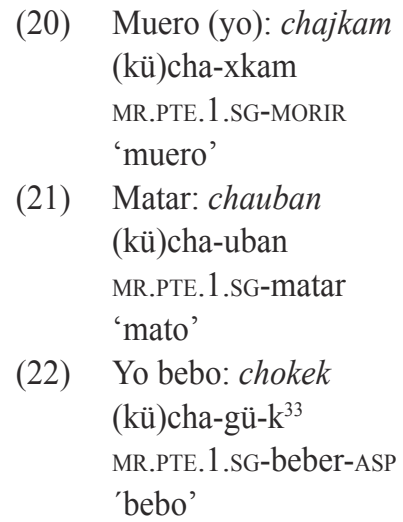

Asimismo, en otros ejemplos, se atestigua la categoría de tiempo con marca morfológica de futuro, en el uso del prefijo chükü- para la primera persona:

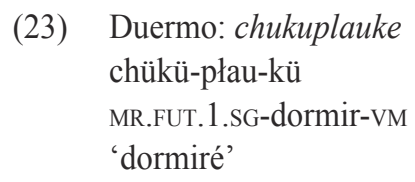

33. La base verbal 'beber' es registrada en las fuentes con alternancia de sonoridad en el fono velar: gü y $k \ddot{u}$. 
La documentación de las lenguas patagónicas en el gabinete de Lafone Quevedo

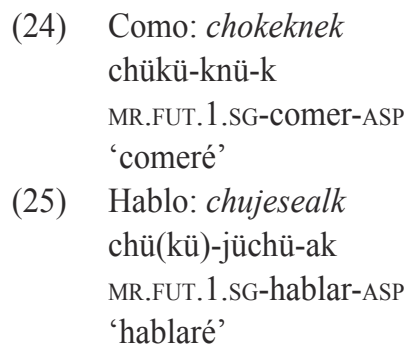

En cambio, solamente hay tres frases verbales que refieren a la segunda persona del singular, en las modalidades imperativa (26) -ver también ejemplo (4)-e interrogativa (27).

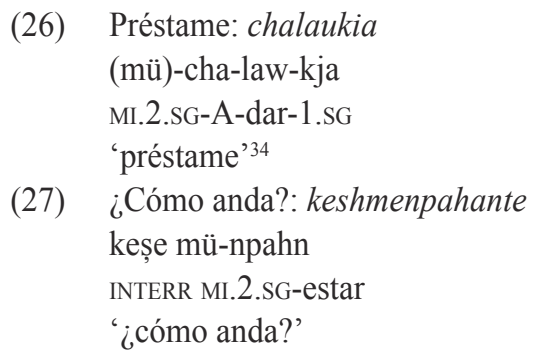

Estas últimas cláusulas ofrecen ejemplos del ordenamiento de constituyentes en oraciones simples: (26) (OD)-V-OI y (27) INTERR-V. Además, la frase (28) confirma el orden canónico de los elementos en oraciones ecuativas:

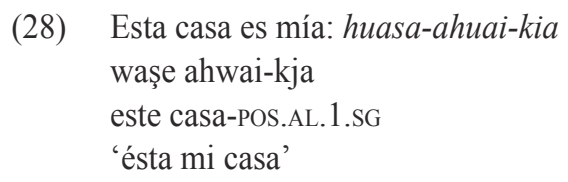

Por otro lado, junto con la reproducción de las expresiones a'a 'sí' y kette sasse- kette attke 'más mejor', algunas cláusulas reflejan emisiones con usos pragmáticos propios de la interacción de la conversación cotidiana. Destacamos que el adverbio katük (transcripto kette por Lafone Quevedo) sólo será registrado casi un siglo después por Casamiquela (1983, p. 143). En nuestro análisis,

34. Los marcadores de $\mathrm{O}$ (objeto) en verbos transitivos comportan el mismo paradigma de morfemas que se aplica para la posesión alienable. 


(29) Kette sasse
katük şaşe
más ese
'más ese'
Kette attke
katük hatkü
más bueno
'más bueno'

En síntesis, y aun en su brevedad, el vocabulario que Lafone Quevedo compiló hace importantes contribuciones al conocimiento de la lengua, ratificando, por un lado, lo que se conoce actualmente a partir de otras fuentes, por otro, ampliando con nuevos elementos el análisis del sistema tanto en el plano morfológico como en el léxico, el sintáctico y el fonético-fonológico.

\section{Conclusiones}

A modo de cierre, destacamos la relevancia para los estudios historiográfico-lingüísticos de la recuperación de este manuscrito y el análisis de los criterios y procedimientos de producción utilizados por Lafone Quevedo.

En cuanto al documento presentado, solo se conocían tres palabras que el propio Lafone Quevedo había publicado (las equivalencias de 'agua', 'cabeza', 'padre') y la declinación de la posesión en las tres personas del singular en los dos últimos sustantivos (1900, p. 107). Su vocabulario incrementa notoriamente el corpus de expresiones existentes en la época, considerándose además que entre su recopilación y la inmediatamente subsiguiente, desarrollada por Lehmann-Nitsche, transcurrieron veinte años.

Como hemos analizado, junto con la transcripción de los datos el autor efectúa algunas hipótesis (de manera intuitiva y como notas al margen de los lexemas $\mathrm{y}$ frases) que han sido corroboradas por estudios posteriores sobre esta lengua indígena. Percibe categorías, segmenta morfemas y algunos valores fonéticos y suprasegmentales además de registrar elementos que no se habían recopilado en las otras fuentes existentes hasta entonces, como por ejemplo el posesivo alienable -ilga, la estructura comparativa katük y un equivalente para 'luna': york sólo documentado en su vocabulario.

Fue además este filólogo, mucho antes que Lehmann-Nitsche (1913), quien enfocó el problema del agrupamiento de las lenguas patagónicas, intentando fundamentar su perspectiva mediante el acopio y el análisis de datos originales. También aportó a la consolidación de una metodología de contraste léxico aplicada a estas lenguas, en la cual las expresiones se ordenan con indicación del recopilador de cada entrada en un formato muy similar al que utilizarían 
posteriormente otros especialistas en el país. Cabe destacar en Lafone Quevedo, también, una propuesta de comparación de alcance más amplio, que no sólo se aplicó al trabajo en gabinete sino que también modeló la documentación realizada en el campo.

El análisis propuesto permitió reconstruir las prácticas, objetivos e instrumentalidades empleadas por quien fuera considerado un reconocido exponente del americanismo decimonónico en el Cono Sur. Desde nuestro punto de vista, el examen de las producciones y reflexiones de Lafone Quevedo acerca del günün a iajüch permite clarificar mejor sus hipótesis en relación con las lenguas de esta región del continente, así como los mecanismos específicos que diseñó para confirmarlas. En otro plano, la investigación contribuye a reponer las tramas de relaciones y los focos de investigación del mundo académico local, en el marco de los debates de la comunidad científica internacional acerca del "hombre americano". En este sentido, el argumento lingüístico adoptado por Lafone Quevedo y sustentado no sólo por datos históricos, sino contemporáneos, le permitió desplegar razonamientos que guiaban el análisis hacia problemas situados en un amplio campo de intereses de estudio con proyecciones sudamericanas. Esto posiciona a Lafone Quevedo como uno de los pioneros de la lingüística argentina, en gran parte desarrollada a partir del abordaje de las diversas lenguas originarias. *

* Manuscrit reçu en février 2019, accepté pour publication en juin 2019.

\section{Referencias bibliográficas}

AAVV

1921 “Dr. Samuel Lafone Quevedo. Director del Museo (1906-1920). Noticia bio-bibliográfica", Revista del Museo de La Plata, 25, p. ix-xxiv.

1962 "Homenaje a Samuel Lafone Quevedo", Cuadernos del Instituto Nacional de Investigaciones Folklóricas, 3, p. 9-34.

BOMAN Eric

1922 "Samuel Alejandro Lafone Quevedo. Nécrologie", Journal de la Société des Américanistes de Paris, Nouvelle Série, 14, p. 205-213.

BRINTON Daniel G.

1886 "On polysynthesis and incorporation as characteristics of American languages author(s)", Proceedings of the American Philosophical Society, 23 (121), p. 48-86, https://www.jstor.org/stable/982913, consultado el 10/12/2019.

BRIDGES Thomas

1987 [1933] Yamana-English Dictionary, Zagier \& Urruty, Buenos Aires.

Burmeister Carlos

1891 "Breves datos de una excursión a la Patagonia", Revista del Museo de La Plata, 2, p. 275-288. 
Casamiquela Rodolfo

1983 Nociones de gramática del gününa küne, CNRS, Paris.

Cox Guillermo

1863 Viaje en las rejiones septentrionales de la Patagonia. 1862-1863, Imprenta Nacional, Santiago de Chile.

FALKNER Thomas

1774 A description of Patagonia, and the adjoining lands of South America, C. Pugh, London.

1911 Descripción de la Patagonia y de las partes contiguas de la América del Sur, Universidad Nacional de La Plata, Buenos Aires.

FARro Máximo

2009 La formación del Museo de La Plata. Coleccionistas, comerciantes, estudiosos y naturalistas viajeros a fines del siglo XIX, Prohistoria, Rosario.

2012 "Imágenes de cráneos, retratos antropológicos y tipologías raciales. Los usos de las primeras colecciones de fotografías del Museo de La Plata a fines del siglo XIX", in Tatiana Kelly y Irina Podgorny (dirs), Los secretos de Barba Azul. Fantasías y realidades de los archivos del Museo de La Plata, Prohistoria, Rosario, p. 69-103.

2013 "Las lenguas indígenas como objeto de colección. Notas acerca de los trabajos lingüísticos de Samuel A. Lafone Quevedo a fines del siglo XIX”, Revista de Indias, 73, 258, p. 525-552.

Furlong CARDIFF Guillermo

1964 Samuel A. Lafone Quevedo, Ediciones Culturales Argentinas, Buenos Aires. GuNN Robert L.

2015 Ethnology and empire. Languages, literature, and the making of the North American borderlands, New York University Press, New York.

Hale Horatio

1846 United States Exploring Expedition during the year 1838, 1839, 1840, 1841, 1842 under the command of Charles Wilkes, U.S.N., vol. VII, Lea and Blanchard, Philadelphia.

\section{HARRINGTON Tomás}

(s. f.) Vocabulario gününa küne, transcripción realizada por Pedro Viegas Barros, ms. IMBELLONI José

1936 "Introducción. Lenguas indígenas de la República Argentina”, in Ricardo Levene (dir.), Historia de la Nación Argentina. Desde los orígenes hasta la organización definitiva en 1862, Universidad de Buenos Aires, Buenos Aires, vol. 1 , p. 177-205.

Kate Herman F. C. ten

1906 "Matériaux pour servir à l'anthropologie des Indiens de la République Argentine", Revista del Museo de La Plata, 12, p. 31-64.

LAFONE Quevedo Samuel A.

1892a "Las lenguas argentinas y el Museo de La Plata", La Nación, 8 de octubre de 1892 , p. 1.

$1892 b$ "Instrucciones del Museo de La Plata para los colectores de vocabularios indígenas", Revista del Museo de La Plata, 3, p. 401-416. 
La documentación de las lenguas patagónicas en el gabinete de Lafone Quevedo

1895 "Lenguas americanas. Cuatro monografías", La Nación, 18 de diciembre de 1895 , p. 3.

1898a Vocabulario Puelche-Guenaken, base el de Lafone Quevedo 1896, archivo histórico del Museo de La Plata, Buenos Aires, Fondo Lafone Quevedo, Carpeta 42 Lenguas patagónicas, Ms. 9.

1898b Vocabulario Guenaken-Español, archivo histórico del Museo de La Plata, Buenos Aires, Fondo Lafone Quevedo, Carpeta 42 Lenguas patagónicas, Ms. 10.

1898c Los Indios Puelche-Guenaken y su lengua (Pampas), Museo Mitre, Buenos Aires, ms.

1898d Tesoro de Catamarqueñismos. Nombres de lugar y apellidos indios con etimologías y eslabones aislados de la lengua Cacana, Coni, Buenos Aires.

1900 "La raza pampeana y la raza guaraní, in Samuel A. Lafone Quevedo y Félix Outes (comps), Primera reunión del Congreso Científico Latinoamericano celebrada en Buenos Aires del 10 al 20 de 1898 por iniciativa de la Sociedad Cientifica Argentina. V. Trabajos de las 4ta sección (Ciencias antropológicas y sociológicas), Compañía Sud-Americana de Billetes de Banco, Buenos Aires, p. 27-135.

1912 Pronominal classification of certain South American Indian stocks, to be read before the XVIIIth International Congress of Americanists to be held in London, May 1912, Coni, Buenos Aires.

La Grasserie Raoul de

1902 “Contribution à l'étude des langues de la Patagonie. Vocabulaire pehuenche", Congrès international des américanistes. XII session, tenue à Paris en 1900, Ernest Leroux, Paris, p. 339-354.

LeHMANN-Nitsche Roberto

1913 "El grupo lingüístico Tshon de los territorios magallánicos”, Revista del Museo de La Plata, 22, p. 217-276.

1915 Carta a Samuel Lafone Quevedo, $1^{\circ}$ de marzo de 1915, archivo histórico del Museo de La Plata, Dirección del Instituto del Museo, IMD, Fondo Lafone Quevedo, Carpeta 14, Carta 47.

1916 Carta a Samuel Lafone Quevedo, Tehuel Malal, 7 de febrero de 1916, legado Lehmann-Nitsche, Ibero-Amerikanisches Institut, Berlin, N-0070 b 817.

1922 "El grupo lingüístico 'Het' de la pampa argentina", Revista del Museo de La Plata, 27, p. 10-85.

1930 "El idioma chechehet (Pampa bonaerense). Nombres propios", Revista del Museo de La Plata, 32, p. 277-291.

MaLvestitti Marisa

2012 Mongeleluchi zungu. Los textos araucanos documentados por Roberto Lehmann-Nitsche, Ibero-Amerikanisches Institut/Gebr. Mann Verlag, Berlin.

2014 “Ahúnik'onk'. Un vocabulario de la lengua tehuelche documentado por Roberto Lehmann-Nitsche", Indiana, 31, p. 377-408.

2015 "Palabras selknam. El vocabulario Ōōna recopilado por Roberto LehmannNitsche", Magallania, 43 (1), p. 69-89.

2018 "Dimensiones teórico-metodológicas en dos vocabularios del mapuzungun registrados en Puelmapu", in Beatriz Neumann (ed.), Encuentro textual. 
Ensayos sobre literaturas y lenguas, EDUPA/ILLPAT/UNPSJB, Trelew, t. 2, p. 177-193.

Malvestitti Marisa y María Emilia ORden

2014 Günün a yajütshü. El vocabulario puelche documentado por Roberto LehmannNitsche, EDULPam/Instituto Ibero-Americano de Berlín, Santa Rosa.

Milanesio Domenico

1898 La Patagonia, lingua, industria, costumi e religione dei Patagoni, Escuela Profesional de Tipógrafos de Colegio Pio IX de Artes y Oficios, Buenos Aires.

Mitre Bartolomé

1909 Catálogo razonado de la sección Lenguas americanas, Tomos 1-3, Imprenta de Coni Hermanos, Buenos Aires.

Moreno Francisco Pascacio

1876 "Viaje a la Patagonia septentrional", in Anales de la Sociedad Cientifica Argentina, Tomo 1, Imprenta Coni, Buenos Aires.

1879 Viaje á la Patagonia Austral. Emprendido bajo los auspicios del gobierno nacional, 1876-1877, Imprenta de la Nación, Buenos Aires [2 $2^{\mathrm{a}}$ ed.].

Orbigny Alcide d'

1839 Voyage en Amérique méridionale, Tomo IV, Pitois-Levrault, Paris.

ORden María Emilia

2017 Descripción de la lengua günün a iajüch, tesis doctoral, Departamento de Humanidades, Universidad Nacional del Sur, Bahía Blanca, ms.

Outes Félix y Carlos BRUCH

1910 Los aborígenes de la República Argentina. Manual adaptado a los programas de las Escuelas Primarias, Colegios Nacionales y Escuelas Normales, Ángel Estrada, Buenos Aires.

Podgorny Irina y Maria Margaret Lopes

2013 "Trayectorias y desafíos de la historiografía de los museos de historia natural en América del Sur", Anais do Museu Paulista, 21 (1), p. 15-25.

RoJAs Ricardo

1960 [1917] Historia de la literatura argentina, Tomo I, Kraft, Buenos Aires.

Viegas Barros José Pedro

2015 Proto-Chon. Fonología, morfología y léxico, tesis doctoral, Facultad de Filosofía y Letras, Universidad de Buenos Aires, ms.

Vignati Milcíades Alejo

1942 "Iconografía aborigen I, Sayhueque, Inacayal y Foyel”, Revista del Museo de La Plata, Segunda Serie, 10, p. 13-48.

VizCaino Sergio

2011 "Cartas para Florentino desde la Patagonia. Crónica de la correspondencia édita entre los hermanos Ameghino (1887-1902)", Publicación Especial, 12 ("Vida y obra de Florentino Ameghino", Juan C. Fernícola, Aldo R. Prieto y Darío G. Lazo [eds]), Asociación Paleontológica Argentina, p. 51-67. 